\title{
Peertechz
}

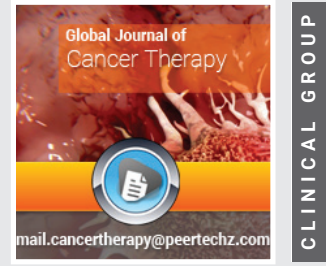

\section{Brain Tumor: An overview of the basic clinical}

\section{manifestations and treatment}

\author{
Abolanle AA Kayode ${ }^{1 *}$, Amina Shahzadi ${ }^{2}$, Muhammad \\ Akram $^{3}$, Hina Anwar ${ }^{3}$, Omowumi T Kayode ${ }^{4}$, Omowumi 0 \\ Akinnawo $^{1}$ and Sunday 0 Okoh $^{5}$ \\ 'Department of Biochemistry, Babcock University, Ilishan-Remo, Ogun State, Nigeria \\ ${ }^{2}$ Department of Eastern Medicine, University of Poonch, Rawalakot Azad Jammu and Kashmir, \\ Pakistan \\ ${ }^{3}$ Department of Eastern Medicine, Government College University Faisalabad-Pakistan \\ ${ }^{4}$ Department of Biochemistry, Landmark University, Omu-Aran, Kwara State, Nigeria \\ ${ }^{5}$ Department of Chemical Sciences, Faculty of Science and Science Education, Anchor University, \\ Lagos, Nigeria
}

Received: 23 September, 2020

Accepted: 19 October, 2020

Published: 20 October, 2020

*Corresponding author: Kayode AA Abolanle, Department of Biochemistry, Babcock University, IlishanRemo, Ogun State, Nigeria, Tel: +234-8038272670; E-mail: bolakayot@gmail.com; kayodeab@babcock. edu.ng

Keywords: Brain tumor; Clinical presentation; Diagnostic tools; Risk factors; Therapy

ORCID: https://orcid.org/0000-0002-7101-9177

https://www. peertechz.com

\section{Check for updates}

\begin{abstract}
We review the basic clinical manifestation, diagnosis and management of brain tumor.

Google search was done by using different terms associated with brain tumor and different databases were used, such as Google Scholar, Cochrane Database, and Science Direct etc.

In spite of the fact that clinical manifestations fluctuate on the basis of category, magnitude and site of tumor, the most common clinical features reported are persistent headache, seizures, nausea and vomiting, loss of consciousness, dizziness, mood fluctuation, cognitive problems, visual defects, weakness of body parts, difficulty with speech and language, and hearing impairment. Apart from neurologic examination, diagnostic approaches include Computed Tomography (CT) scan, MRI and biopsy.

Treatment strategies, determined by a variety of factors, include surgery, radiotherapy, chemotherapy and indicative therapy. This mini-review summarizes brain tumor biology as regards its classification, grading, risk factors, clinical presentation, diagnostic tools and treatment modalities.
\end{abstract}

\section{Background}

Brain tumor constitutes $2-3 \%$ of all malignant neoplasms and nearly $85-90 \%$ of all primary CNS tumors, with an estimated five-year survival rate of up to $35 \%$ for malignant tumors and about $90 \%$ for benign tumors [1]. Studies put brain tumors in the list of most common malignancy after leukemia in children with an incidence of up to $25 \%[2,3]$. Growing prevalence rate in developed countries may be attributed to availability of advanced techniques for detection and diagnosis when compared to that of developing countries where most people have limited access to equipment for early detection. This results in undiagnosed and unregistered cases, thereby, decreasing the level of incidence and prevalence reported [4]. Brain tumors are diagnosed at the age of 3-12 years in children and $40-70$ years in adults. Brain tumors range from benign to malignant and eventually to metastatic tumors. Metastatic brain tumors are more prevalent in adults [5]. Carcinomas metastasizing to brain include lung, breast, skin (melanoma), kidney and colon with predominant contribution made by lung cancer (small cell lung cancer), accounting for about one half of all disseminated cases, according to reports from various 
studies [6-9]. Brain tumors are graded from I-IV by World Health Organization (WHO) on the basis of their catastrophic potentials [10]. The tittle, low grade tumor (I \& II) is appropriate for tumors with excellent and good prognosis in contrast to high grade tumors (III \& IV) which tend to be malignant, thereby, leading to serious complications [11]. Primary brain tumor categories owing to cell type from which they originate are: gliomas; having their association with glial cells, meningiomas; abnormal growth of meninges, ependymomas; originate from cells (ependymocytes) lining the CSF filled ventricles, astrocytomas; developing from star-shaped glial cells (astrocytes) and so on. The majority of primary brain tumors are gliomas, a class of tumors evolving from supporting cells of the nervous system (glial cells/ neuroglia), with an integer of nearly 33\% [12]. Gliomas have various histological subtypes grading from pilocytic astrocytoma (innocent and least offensive) to glioblastoma (drastic and terminal illness) [13]. Normally, gliomas are tumors of adults with their optimal presentation beyond 45 years of age, although it can come up at any other period in a lifetime. Susceptibility of men to gliomas has been reported as well as other brain tumors except meningiomas which are more frequent among females [14].

\section{Main text}

\section{Risk factors}

Etiology of primary brain tumors is still obscure, however, there are some risk factors ascribed for population susceptibility to tumors (Table 1). Besides its reliance upon cellular origin and location of tumor, probability of brain tumors increases with age, with the utmost frequency between 55 and 64 years of life. Brain tumors incidence is distributed between the two genders in a male to female ratio of 1.5:1, excluding meningioma which are virtually customary to the female folks only [15]. Literature shows propensity of white population in the US to gliomas as well. There have been some inconsistencies regarding the risk factors of brain tumors compared to other body tumors. Despite the controversy surrounding the risk factors, prior subjection of the head to high dose of ionizing radiations such as $\mathrm{X}$ - rays, CT scans [16] and MRI, especially for therapeutic purpose are some of the risk factors implicated in the development of brain tumors [17-19]. It is has been reported that children exposed to radiotherapy for the treatment of various diseases are vulnerable

Table 1: Risk Factors associated with brain tumor

\section{Validated Risk Factors}

Environmental

Prior exposure to high-dose lonizing radiations Genetic

Neurofibromatosis types $1 \& 2$

Li-Fraumeni syndrome

Von Hippel-Lindau disease

Tuberous sclerosis

Turcot syndrome

Cowden disease

Gorlin syndrome

\section{Unverified Risk Factors}

Environmental

Cell phones Alcohol

Virus- induced

Infections

Smoking

Exposure to Vinyl chloride,

Pesticides, Rubber etc.

Dietary N-nitroso compounds

Exposure to Aspartame Exposure to

Electromegnatic fields Genetic

Genetic polymorphisms (e.g. XRCC1) to brain tumors within an interval of practically 15 years after exposure. Radiation-induced brain tumors development are relatively common among young ones experiencing leukemia. Although genetics plays part, there are some inherited cancerous conditions such as neurofibromatosis types I \& II, Von Hippel- Lindau disease, Tuberous sclerosis, Li-Fraumeni syndrome, Coden disease, Gorlin syndrome, Turcot syndrome making a contribution of up to $2 \%$ to brain tumor [20,21]. Publications proposing contribution of other risk factors i.e. cell phones, viruses, allergens, alcohol, N-nitroso compounds, infections, chemicals and smoking on subject of establishment of brain tumors have been conflicting. Although no specific statement regarding cell phone as a risk factor is available [22], the World Health Organization (WHO) suggests restricted usage of mobile phones considering them feasibly noxious.

\section{Clinical presentation}

Clinical manifestations of brain tumors are baffling and fluctuate substantially depending upon the category, locality, bulk \& rate of growth of tumor [23]. With respect to pathogenesis, clinical features can be graded into raised intracranial pressure and focal, a characteristic of indigenous tissue destruction $[19,24]$. To date, the most reported symptom experienced by patients have been headache [25]. Headache being categorized as a general feature is one of the ordinary complaints experienced by nearly one half of victims. Headache presents itself as an inceptive symptom in most of cases. Besides headache and seizures other manifestations include nausea and emesis, ataxia, visual disturbances, personality and behavior changes, speech difficulties, altered consciousness, sleep disturbances, drowsiness, fatigue, memory problems, tingling sensations in some body parts $[25,26]$. Focal symptoms in the areas of brain involved include:

\section{Frontal lobe}

Personality and behavior changes, Cognitive dysfunction, Memory loss, Contralateral motor loss.

\section{Parietal lobe}

Spatial disorientation, Writing, naming and drawing difficulties, Aphasia, Recognition problems.

\section{Occipital lobe}

Unilateral/ bilateral vision loss, Visual field defects, Illusions, Hallucinations, Blurred vision.

\section{Temporal lobe}

Short and long-term memory problems, speech and language deficits, Emotional changes e.g. aggressiveness, Difficulty in understanding words.

\section{Cerebellum}

Ataxia, Difficulty with fine motor skills.

\section{Brainstem}

Difficulty in swallowing, Facial paresis/ tingling, Double vision. 


\section{Diagnosis}

Comprehensive medical history combined with thorough general physical examination, coupled with neurologic examination, relevant imaging modalities and histopathological assay are very crucial in the establishment of the diagnosis. While performing neurologic examination, the neurosurgeon assesses vision, coordination, reflexes, hearing, orientation, muscle tone etc. Aside from regular MRI which is a primary tool, other imaging modalities of note include gadolinium enhanced-MRI, functional MRI, perfusion MRI, CT scan, PET-CT scan [27]. Depending upon the requirements, further diagnostic tools can be lumbar puncture/spinal tap, stereotactic biopsy, angiogram, molecular assay, myelogram and craniotomy. MRI which uses strong magnetic fields rather than $\mathrm{X}$-rays/ ionizing radiations to produce transparent depiction, is a desired imaging technique followed by other diagnostic tools [10]. Although MRI is a central imaging tool in patients, where MRI is not a desirable due to any reason (obesity, indwelling implants, catheters, fear of close spaces), CT scan can be used as an option. Besides radiology (MRI / PET-CT scan etc.) that boasts striking worth in diagnosis, histopathology is imperative for evaluation of variety of tumor making the diagnosis certain.

\section{Treatment}

Elements that determine therapeutic approaches can be grouped into tumor's extent, category, grade, site coupled with patient's age, general fitness, comorbidity and their choice of treatment [28]. A multidisciplinary team consisting of neurosurgeon, medical specialist, medical oncologist, neurosurgeon, radiation oncologist and nutritionist design the schedule of treatment. Regular remedial plans include scrutiny, symptomatic treatment, surgery, radiotherapy, chemotherapy, targeted therapy, physiotherapy exclusively/or in combination. Surgical removal being typically the major one is the mainstay of treatment in most of the cases, frequently required solely in benign ones [29,30]. The added advantage of surgery is the provision of tissue for histopathology thereby serving in the determination of further treatment. Also in cases, where patient cannot be cured by surgery, excision of tumor assuages the burden of symptoms ascribed to pressure of growth. Inoperable growths because of location/or other factors, restricts the application of surgery. High-grade tumors often entail a combination of surgery, radiotherapy and chemotherapy [30,31]. Radiotherapy (treatment with radiations (high-energy beams)) generally accompanied by surgery is classified into external-beam radiotherapy, internal radiotherapy/or brachytherapy, conventional radiotherapy, 3-D conformal radiotherapy, intensity modulated radiotherapy, proton therapy and stereotactic radiosurgery, of which the common one is external- beam radiotherapy. Often accompanied by surgery, regular chemotherapy (a form of systemic therapy) can be directed singly/concomitantly with targeted therapy by medical oncologist. Contemporary therapy comprise of radiotherapy and chemotherapy as the standard way of treating inoperable cases as well as in cases of primary malignant tumors accompanied by surgery. In recurrent cases, it is also known for its relevant worth. Chemotherapy regimens regularly divided in cycles given over a scheduled interval of time can be taken intravenously or orally. Targeted therapy, another type of systemic therapy, categorized into two main types, basically attacks the tumor's specific proteins, genes and the habitat that facilitates tumor's growth and survival without causing damage to normal cells. Alternating electric field therapy carried out by Optune (a noninvasive portable gadget) is also brought into consideration as a therapeutic tool for glioblastomas. Besides the afore mentioned treatment strategies, the patient is also subjected to other treatment protocols i.e. regular follow up, rehabilitation therapy in addition to palliative/ supportive care [32].

\section{Conclusion}

Brain tumor, a subject matter bearing a lot of disharmony and hesitancy, calls for further epidemiological exploration to be carried out and elucidated conservatively. Though brain tumors are not frequent among adults, their frequency is growing possibly due to advanced diagnostic techniques available in developed countries.

\section{References}

1. Neugut Al, Sackstein P, Hillyer GC, Jacobson JS, Bruce J, et al. (2019) Magnetic Resonance Imaging-Based Screening for Asymptomatic Brain Tumors: A Review. Oncologist 24. Link: https://bit.ly/2T4tfUb

2. Van Maele-Fabry G, Gamet-Payrastre L, Lison D (2017) Residential exposure to pesticides as risk factor for childhood and young adult brain tumors: a systematic review and meta-analysis. Environ Int 106: 69-90. Link: https://bit.ly/2T4theL

3. Ullrich NJ, Pomeroy SL, Kapur K, Manley PE, Goumnerova LC, et al. (2015) Incidence, risk factors, and longitudinal outcome of seizures in longterm survivors of pediatric brain tumors. Epilepsia 56: 1599-1604. Link: https://bit.ly/37nEWOf

4. Khan I, Bangash M, Baeesa S, Jamal A, Carracedo A, et al. (2015) Epidemiological trends of histopathologically WHO classified CNS tumors in developing countries: systematic review. Asian Pac J Cancer Prev 16: 205216. Link: https://bit.ly/2Hh6Pg4

5. Fox BD, Cheung VJ, Patel AJ, Suki D, Rao G (2011) Epidemiology of metastatic brain tumors. Neurosurg Clin N Am 22: 1-6. Link: https://bit.ly/2FGyyq3

6. Lin X, DeAngelis LM (2015) Treatment of brain metastases. J Clin Oncol 33: 3475-3484. Link: https://bit.ly/348YXpD

7. Davis FG, Dolecek TA, McCarthy BJ, Villano JL (2012) Toward determining the lifetime occurrence of metastatic brain tumors estimated from 2007 United States cancer incidence data. Neuro Oncol 14: 1171-1177. Link: https://bit.ly/3dHuCSy

8. Weber GF, Ashkar S (2000) Molecular mechanisms of tumor dissemination in primary and metastatic brain cancers. Brain Res Bull 53: 421-424. Link: https://bit.ly/3o0RhOi

9. Stelzer KJ (2013) Epidemiology and prognosis of brain metastases. Surgical Neurology International 4: S192. Link: https://bit.ly/3dAESMg

10. Mabray MC, Barajas RF, Cha S (2015) Modern brain tumor imaging. Brain Tumor Res Treat 3: 8-23. Link: https://bit.ly/31kPj1q

11. Guzmán-De-Villoria JA, Mateos-Pérez JM, Fernández-García $P$, Castro $E$, Desco M (2014) Added value of advanced over conventional magnetic resonance imaging in grading gliomas and other primary brain tumors. Cancer Imaging 14: 35. Link: https://bit.ly/3knFTtq 
12. Ostrom QT, Gittleman H, Stetson L, Virk S, Barnholtz-Sloan JS (2018) Epidemiology of intracranial gliomas. Prog Neurol Surg 30: 1-11. Link: https://bit.ly/31k3tjs

13. Ho VK, Reijneveld JC, Enting RH, Bienfait HP, Robe P, et al. (2014) Changing incidence and improved survival of gliomas. Eur J Cancer 50: 2309-2318. Link: https://bit.ly/3kcdl6b

14. Longstreth W, Dennis LK, McGuire VM, Drangsholt MT, Koepsell TD (1993) Epidemiology of intracranial meningioma. Cancer 72: 639-648. Link: https://bit.ly/3k9LAel

15. Bondy ML, Scheurer ME, Malmer B, Barnholtz-Sloan JS, Davis FG, et al. (2008) Brain tumor epidemiology: consensus from the Brain Tumor Epidemiology Consortium. Cancer 113: 1953-1968. Link: https://bit.ly/347Ap02

16. Davis F, Il'yasova D, Rankin K, McCarthy B, Bigner DD (2011) Medical diagnostic radiation exposures and risk of gliomas. Radiat Res 175: 790-796. Link: https://bit.ly/2HdXfKW

17. Braganza MZ, Kitahara CM, Berrington de González A, Inskip PD, Johnson $\mathrm{KJ}$, et al. (2012) lonizing radiation and the risk of brain and central nervous system tumors: a systematic review. Neuro Oncology 14: 1316-1324. Link: https://bit.ly/3m0JJcl

18. Picano E, Vano E, Domenici L, Bottai M, Thierry-Chef I (2012) Cancer and noncancer brain and eye effects of chronic low-dose ionizing radiation exposure. BMC cancer 12: 157. Link: https://bit.ly/34bKV6E

19. Allen Perkins M, Liu G (2016) Primary Brain Tumors in Adults: Diagnosis and Treatment. Am Fam Physician 93: 211-217. Link: https://bit.ly/31kAaNK

20. Farrell CJ, Plotkin SR (2007) Genetic causes of brain tumors: neurofibromatosis, tuberous sclerosis, von Hippel-Lindau, and other syndromes. Neurol Clin 25: 925-946. Link: https://bit.ly/3dG13QZ

21. Hemminki K, Tretli S, Sundquist J, Johannesen TB, Granström C (2009) Familial risks in nervous-system tumours: a histology-specific analysis from Sweden and Norway. Lancet Oncol 10: 481-488. Link: https://bit.ly/37nGpnJ

22. Ostrom QT, Barnholtz-Sloan JS (2011) Current state of our knowledge on brain tumor epidemiology. Current Neurology and Neuroscience Reports 11: 329335. Link: https://bit.ly/2T5II7V
23. Adams C, Sullivan J, Vitaz TW (2015) Clinical Presentation of Brain Tumors Molecular Considerations and Evolving Surgical Management Issues in the Treatment of Patients with a Brain Tumor 309. Link: https://bit.ly/3dF2770

24. Lapointe S, Perry A, Butowski NA (2018) Primary brain tumours in adults. Lancet 392: 432-446. Link: https://bit.ly/2HhtmJH

25. Perkins A, Liu G (2016) Primary Brain Tumors in Adults: Diagnosis and Treatment. American Family Physician 93. Link: https://bit.ly/31n7oMp

26. Comelli I, Lippi G, Campana V, Servadei F, Cervellin G (2017) Clinica presentation and epidemiology of brain tumors firstly diagnosed in adults in the Emergency Department: a 10-year, single center retrospective study. Ann Transl Med 5: 269. Link: https://bit.ly/2T69zPV

27. Fink JR, Muzi M, Peck M, Krohn KA (2015) Multimodality brain tumor imaging: MR imaging, PET, and PET/MR imaging. J Nucl Med 56: 1554-1561. Link: https://bit.ly/3kaEZkd

28. Tsao MN, Rades D, Wirth A, Lo SS, Danielson BL, et al. (2012) Radiotherapeutic and surgical management for newly diagnosed brain metastasis (es): An American Society for Radiation Oncology evidence-based guideline. Pract Radiat Oncol 2: 210-225. Link: https://bit.ly/2HeFTgQ

29. Eberlin LS, Norton I, Orringer D, Dunn IF, Liu X, et al. (2013) Ambient mass spectrometry for the intraoperative molecular diagnosis of human brain tumors. Proc Natl Acad Sci U S A 110: 1611-1616. Link: https://bit.ly/37iG7yp

30. Elkady A, Soliman MAR, Ali AM (2020) Clinical Outcomes infratentoria Meningioma Surgery in a Developing Country. World Neurosurg 137 e373-e382. Link: https://bit.ly/31gVKT5

31. Young RM, Jamshidi A, Davis G, Sherman JH (2015) Current trends in the surgical management and treatment of adult glioblastoma. Ann Transl Med 3 : 121. Link: https://bit.ly/3o0T5a2

32. Kanter C, D'Agostino NM, Daniels M, Stone A, Edelstein K (2014) Together and apart: providing psychosocial support for patients and families living with brain tumors. Support Care Cancer 22: 43-52. Link: https://bit.ly/37pCN4R

Discover a bigger Impact and Visibility of your article publication with Peertechz Publications

\section{Highlights}

* Signatory publisher of ORCID

* Signatory Publisher of DORA (San Francisco Declaration on Research Assessment)

* Articles archived in worlds' renowned service providers such as Portico, CNKI, AGRIS, TDNet, Base (Bielefeld University Library), CrossRef, Scilit, J-Gate etc

* Journals indexed in ICMJE, SHERPA/ROMEO, Google Scholar etc.

* OAI-PMH (Open Archives Initiative Protocol for Metadata Harvesting)

* Dedicated Editorial Board for every journal

* Accurate and rapid peer-review process

* Increased citations of published articles through promotions

* Reduced timeline for article publication

Submit your articles and experience a new surge in publication services (https://www.peertechz.com/submission).

Peertechz journals wishes everlasting success in your every endeavours.

Copyright: @ 2020 Abolanle KAA, et al. This is an open-access article distributed under the terms of the Creative Commons Attribution License, which permits unrestricted use, distribution, and reproduction in any medium, provided the original author and source are credited.

Citation: Kayode AAA, Shahzadi A, Akram M, Anwar H, Kayode OT, et al. (2020) Brain Tumor: An overview of the basic clinical manifestations and treatment. Glob J Cancer Ther 6(1): 038-041. DOI: https://dx.doi.org/10.17352/2581-5407.000034 